\title{
Properties and Functional Role of Voltage-Dependent Potassium Channels in Dendrites of Rat Cerebellar Purkinje Neurons
}

\author{
Marco Martina, Gui Lan Yao, and Bruce P. Bean \\ Department of Neurobiology, Harvard Medical School, Boston, Massachusetts 02115
}

\begin{abstract}
We characterized the properties and functional roles of voltage-dependent potassium channels in the dendrites of Purkinje neurons studied in rat cerebellar slices. Using outside-out patches formed $\leq 250 \mu \mathrm{m}$ away from the soma, we found that depolarization-activated potassium channels were present at high density throughout the dendritic tree. Currents required relatively large depolarizations for activation (midpoint, approximately $-10 \mathrm{mV}$ ), had rapid activation and deactivation kinetics, and inactivated partially $(20-70 \%$ over $200 \mathrm{msec}$ ) with both fast (time constant, $15-20 \mathrm{msec}$ ) and slow $(300-400 \mathrm{msec}$ ) components. Inactivating and noninactivating components were both blocked potently by external tetraethylammonium (half-block by $150 \mu \mathrm{M}$ ) and 4 -aminopyridine (half-block by $110 \mu \mathrm{M}$ ). The voltage dependence, kinetics, and pharmacology suggest a predominant contribution by Kv3 family subunits, and immunocytochemical experiments showed staining for both Kv3.3 and Kv3.4 subunits in the dendritic tree. In the proximal dendrite, potassium channels were activated by passively spread sodium spikes recorded at the same position, and experiments using dual recordings showed that the channels serve to actively dampen back-propagation of somatic sodium spikes. In more distal dendrites, potassium currents were activated by voltage waveforms taken from climbing fiber responses, suggesting that they help shape these responses as well. The requirement for large depolarizations allows dendritic Kv3 channels to shape large depolarizing events while not disrupting spatial and temporal summation of smaller excitatory postsynaptic potentials.
\end{abstract}

Key words: Kv3; Kv3.3; Kv3.4; tetraethylammonium; 4-aminopyridine; climbing fiber; Purkinje cell

\section{Introduction}

A growing body of experimental data has shown the presence of voltage-dependent ion channels in the dendrites of neurons (for review, see Johnston et al., 1996; Spruston et al., 1999; Häusser et al., 2000). In some neurons, notably hippocampal pyramidal neurons and layer 5 cortical pyramidal neurons, detailed studies have been made of dendritic sodium channels (Colbert et al., 1997; Jung et al., 1997), calcium channels (Christie et al., 1995; Oakley et al., 2001), and potassium channels (Hoffman et al., 1997; Golding et al., 1999; Bekkers, 2000; Johnston et al., 2000; Korngreen and Sakmann, 2000), and the properties of the channels have been linked with physiological functions, especially in controlling back-propagation of action potentials (Colbert et al., 1997; Jung et al., 1997; Williams and Stuart, 2000; Golding et al., 2001; Stuart and Häusser, 2001; Vetter et al., 2001; Watanabe et al., 2002).

The dendrites of cerebellar Purkinje neurons have active membrane properties (Llinás and Sugimori, 1980; Midtgaard et al., 1993; Callaway and Ross, 1997; Pouille et al., 2000; Womack

\footnotetext{
Received March 6, 2003; revised April 16, 2003; accepted April 18, 2003.

This work was supported by National Institutes of Health Grants NS36855 and NS38312. We are very grateful to Lisa Taylor and Dr. Teresa Perney (Rutgers, The State University of New Jersey, Newark, Center for Molecular and Behavioral Neuroscience) for the kind gift of antibodies to Kv3.3 and helpful comments on this manuscript.

Correspondence should be addressed to Bruce Bean, Department of Neurobiology, Harvard Medical School, 220 Longwood Avenue, Boston, MA 02115. E-mail: bruce_bean@hms.harvard.edu.

Copyright $\odot 2003$ Society for Neuroscience $\quad$ 0270-6474/03/235698-10\$15.00/0
}

and Khodakhah, 2002b). However, Purkinje neurons are strikingly different from other projection neurons studied so far in that their dendrites have a much lower density of sodium channels, and fast somatic action potentials fail to propagate effectively into the dendrites (Stuart and Häusser, 1994; Roth and Häusser, 2001; Vetter et al., 2001). Instead, the regenerative electrical activity in distal Purkinje cell dendrites takes the form of slow calcium-dependent action potentials and long-lasting plateaus (Llinás and Sugimori, 1980; Pouille et al., 2000). Correspondingly, patch-clamp recordings and immunocytochemistry have shown the presence of multiple types of calcium channels in Purkinje cell dendrites (Usowicz et al., 1992; Westenbroek et al., 1995; Yokoyama et al., 1995; Mouginot et al., 1997).

Very little is known about potassium channels in Purkinje neuron dendrites. Current-clamp recordings from dendrites show strong outward rectification, consistent with the presence of large depolarization-activated potassium conductances (Etzion and Grossman, 1998, 2001). Cell-attached patch recordings from the dendrites of cultured Purkinje neurons show the presence of voltage-dependent potassium channels with multiple single-channel conductance levels (Gruol et al., 1989, 1991), but little is known about their distribution, macroscopic kinetics, molecular basis, or functional roles. We used a combined electrophysiological and immunocytochemical approach to characterize the potassium channels in Purkinje cell dendrites, and we explored their functional roles by examining their activation by 
different waveforms of dendritic depolarization arising from either synaptic input or somatic spikes.

\section{Materials and Methods}

Parasagittal slices of $300 \mu \mathrm{m}$ thickness were cut from the cerebella of Long-Evans rats using a vibrating tissue slicer (Ted Pella, Redding, CA). Rats (14-21 d of age) were anesthetized by methoxyflurane before decapitation and removal of the cerebellum. All procedures involving animals were approved by the Harvard Medical Area Standing Committee on Animals. After cutting, slices were incubated at $35^{\circ} \mathrm{C}$ for $20 \mathrm{~min}$ and then stored at room temperature.

During recording, slices were continuously superfused with physiological extracellular solution containing (in $\mathrm{mM}$ ): $125 \mathrm{NaCl}, 25 \mathrm{NaHCO}_{3}$, $2.5 \mathrm{KCl}, 1.25 \mathrm{NaH}_{2} \mathrm{PO}_{4}, 2 \mathrm{CaCl}_{2}, 1 \mathrm{MgCl}_{2}$ and 25 glucose, bubbled with $95 \% \mathrm{O}_{2}$ and $5 \% \mathrm{CO}_{2}$. Slices were visualized with an Olympus BX50WI (Olympus Optical, Tokyo, Japan) upright microscope using infrared differential interference contrast videomicroscopy (Stuart et al., 1993) with an immersion $60 \times$ objective.

Patch pipettes were pulled from borosilicate glass tubing (outer diameter, $1.65 \mathrm{~mm}$; inner diameter, $0.75 \mathrm{~mm}$; Dagan, Minneapolis, MN) and heat polished before use. Pipettes were filled with an internal solution consisting of (in mM): $140 \mathrm{KCl}, 2 \mathrm{MgCl}_{2}, 10$ EGTA, $2 \mathrm{Na}_{2}$ ATP, 10 HEPES, pH adjusted to 7.3 with $\mathrm{KOH}$. In some experiments, $30 \mathrm{~mm} \mathrm{KCl}$ was substituted with $30 \mathrm{~mm} \mathrm{KF}$, which enhanced seal formation and stabilized outside-out patches. Tip resistances in working solutions were 5-11 M $\Omega$. The pipettes were brought close to the target while exerting positive pressure (30-60 millibar). This process helped in cleaning off glial cells that often wrap Purkinje cell dendrites. Purkinje cells were easily identified on the basis of their large size and distinctive morphology. Purkinje cells in the vermis were used for these experiments. Distance of the dendrite from which the patch was formed was measured from the center of the soma and off-line from pictures taken with a CCD camera and frame grabber (Scion, Frederick, MD).

We used outside-out patches for characterizing potassium currents because they allow recording of relatively large currents and also facilitate the application of different drugs to study the pharmacological profile of the channels. A potential disadvantage is that properties of channels might change because of changes in the phosphorylation state of the channels (although ATP was included in the internal solution to minimize such changes) or other consequences of dialysis. To evaluate this issue, in early exploratory experiments, we measured potassium currents from dendrites in the cell-attached configuration. It was not possible to use this configuration routinely, because most neurons were spontaneously active and thus it was impossible to control the membrane voltage. In a limited number of cells that did not show spontaneous firing, we determined activation curves in cell-attached patches using absolute voltages calculated after breaking through into the cell and measuring the resting potential. In seven cell-attached patches on dendrites, the voltage of half-maximal activation was $-7 \pm 3 \mathrm{mV}$ and the slope factor was $20 \pm$ $2 \mathrm{mV}$, similar to the values of $-10 \pm 2 \mathrm{mV}$ and $23 \pm 1 \mathrm{mV}(n=16)$ for outside-out patches on dendrites (parameters from fits of the Boltzmann equation raised to the fourth power).

Recordings were performed at $21-24^{\circ} \mathrm{C}$ using an Axopatch $200 \mathrm{~B}$ amplifier (Axon Instruments, Foster City, CA). Signals were low-pass filtered at 5 or $10 \mathrm{KHz}$ (4-pole low-pass Bessel filter on amplifier) and digitized $(10-20 \mathrm{kHz})$ using a Digidata $1321 \mathrm{~A}$ controlled by pClamp8 software interface (Axon Instruments). Currents were corrected for leak current and capacity transients remaining after electronic capacity compensation using a $\mathrm{P} / 4$ leak correction protocol. Currents from outsideout patches were signal-averaged over three trials when determining current-voltage curves and $\leq 10$ trials when assaying the effect of tetraethylammonium (TEA) or 4-aminopyridine (4-AP) at a single test voltage.

Dual somatic and dendritic recordings were performed with two Axopatch $200 \mathrm{~B}$ amplifiers in voltage or current-clamp (I-clamp fast) mode. Capacitive compensation, series resistance compensation, and supercharging (prediction) were used. In voltage-clamp experiments, the compensation ranged from 75 to $85 \%$. Signals from dual current-clamp recordings were sampled at $20 \mathrm{KHz}$ and filtered at $10 \mathrm{KHz}$. Spontaneous
Table 1. Comparison of potassium currents in outside-out patches from dendrites and somata of cerebellar Purkinje neurons

\begin{tabular}{lcc}
\hline Parameter & Dendrite & Soma \\
\hline Activation & & \\
$\quad$ Midpoint & $-10 \pm 2 \mathrm{mV}(n=16)$ & $-12 \pm 2 \mathrm{mV}(n=18)$ \\
$k / 4$ & $5.8 \pm 0.3 \mathrm{mV}(n=16)$ & $4.5 \pm 0.3 \mathrm{mV}(n=18)$ \\
$\tau(0 \mathrm{mV})$ & $3.1 \pm 0.4 \mathrm{msec}(n=16)$ & $4.3 \pm 0.5 \mathrm{msec}(n=18)$ \\
$\tau(20 \mathrm{mV})$ & $2 \pm 0.1 \mathrm{msec}(n=16)$ & $1.9 \pm 0.2 \mathrm{msec}(n=18)$ \\
Deactivation & & \\
$\tau(-70 \mathrm{mV})$ & $1.1 \pm 0.2 \mathrm{msec}(n=4)$ & $0.8 \pm 0.2 \mathrm{msec}(n=7)$ \\
$\tau(-40 \mathrm{mV})$ & $2.8 \pm 0.9 \mathrm{msec}(n=4)$ & $2.8 \pm 0.4 \mathrm{msec}(n=7)$ \\
Inactivation & & \\
$V_{h}$ & $-37.6 \pm 4.5 \mathrm{mV}(n=6)$ & $-38.8 \pm 4.3 \mathrm{mV}(n=7)$ \\
$k$ & $12 \pm 0.6 \mathrm{mV}(n=6)$ & $15.6 \pm 1.2 \mathrm{mV}(n=7)$ \\
$\tau$ fast & $18.7 \pm 3.3 \mathrm{msec}(n=26)$ & $14 \pm 2.5 \mathrm{msec}(n=15)$ \\
Noninactivating (100 msec) & $55 \pm 2 \%(n=28)$ & $75 \pm 2 \%(n=28)$ \\
Block by $1 \mathrm{~mm}$ TEA & $76 \pm 4 \%(n=10)$ & $79 \pm 3 \%(n=9)$
\end{tabular}

All data are from outside-out patches except the data for inactivation of somatic currents, which are from outsideout nucleated patches. The voltage dependence of the inactivation curve was determined using a 5 sec prepulse. For dendrites, data were confined to patches at a distance from soma of at least $100 \mu \mathrm{m}$ for activation and inactivation and at least $70 \mu \mathrm{m}$ for TEA block. Parameters reported in this table were obtained by averaging values from fitting of individual experiments.

activity was recorded in the presence of $1.2 \mathrm{~mm}$ kynurenate and $100 \mu \mathrm{M}$ picrotoxin to block fast synaptic transmission.

Drugs were applied to patches using quartz microcapillaries in a linear array with control and drug-containing solutions in adjacent capillaries. These experiments were performed using a HEPES-buffered external solution containing (in mM): $140 \mathrm{~mm} \mathrm{NaCl}, 4 \mathrm{~mm} \mathrm{KCl}, 2 \mathrm{~mm} \mathrm{CaCl}_{2}, 1 \mathrm{~mm}$ $\mathrm{MgCl}_{2}, 25 \mathrm{~mm}$ glucose, $10 \mathrm{~mm}$ HEPES, pH adjusted to 7.3, with $\mathrm{NaOH}$.

To construct activation curves, chord conductance $(G)$ was calculated from the peak current assuming ohmic behavior and a reversal potential of $-95 \mathrm{mV}$. Activation and inactivation curves were fit with functions on the basis of the Boltzmann function, $1 /\left(1+\exp \left[ \pm\left(V-V_{h}\right) / k\right]\right)$, where $V$ is the membrane potential, $V_{h}$ is the potential at which the value of the Boltzmann function is 0.5 , and $k$ is the slope factor. Activation curves were fit with a Boltzmann function raised to the fourth power. Inactivation curves were fit with a Boltzmann function plus a constant. The curves shown in figures represent fits to the averaged data obtained from pooling all experiments together. The parameters reported in the text and Table 1 are the values obtained by averaging the results of independent fitting of individual experiments. In principle, this is a better procedure, because when data are averaged before plotting the curves, the apparent slope may be reduced if equally steep curves with slightly different midpoints are averaged. However, the differences between the two sets of parameters were minor.

Data are reported as mean \pm SEM, and error bars in figures also represent SEM. SEMs of fit parameters were obtained by fitting data of individual experiments separately.

Immunocytochemistry. Postnatal 15-16-d-old Long-Evans rats were anesthetized with isoflurane and perfused through the left ventricle with $30 \mathrm{ml}$ of ice-cold saline followed by $200 \mathrm{ml}$ of $4 \%$ paraformaldehyde, $0.2 \%$ picric acid in $0.1 \mathrm{M}$ phosphate buffer, $\mathrm{pH}$ 7.4. The brains were immersed in the same fixative at $4^{\circ} \mathrm{C}$ for $16 \mathrm{hr}$ and then transferred to $30 \%$ sucrose in sodium phosphate buffer for 2-3 d. Twenty-five micrometer thick sagittal sections were cut with a cryostat, mounted on glass slides, and then air-dried and rehydrated in $0.1 \mathrm{M}$ phosphate buffer, $\mathrm{pH}$ 7.4, for at least $40 \mathrm{~min}$. The sections were then treated for $10 \mathrm{~min}$ in $0.1 \mathrm{M}$ PBS, pH 7.4, containing $0.3 \%$ hydrogen peroxide (Sigma, St. Louis, MO) and $0.3 \%$ normal goat serum (Sigma) at room temperature and then rinsed with TNT (0.1 M Tris-HCl, pH 7.5, $0.15 \mathrm{M} \mathrm{NaCl}, 0.05 \%$ Tween 20) two times for $5 \mathrm{~min}$ each. Slices were washed in TNB (TNT plus $1 \%$ goat serum; $20-22^{\circ} \mathrm{C}$ for $1 \mathrm{hr}$ ) to minimize unspecific binding and then incubated overnight at $4^{\circ} \mathrm{C}$ with primary diluted in TNB. Dilutions were 1:1000 for mouse anti-calbindin (Sigma), 1:100 for rabbit anti-Kv3.4 (Alomone Labs, Jeruselum, Israel), and 1:300 for rabbit anti-Kv3.3 (kind gift from Lisa Taylor and Dr. Teresa Perney). Afterward, sections were rinsed in TNT (three times for 10 min each) and then incubated with the 

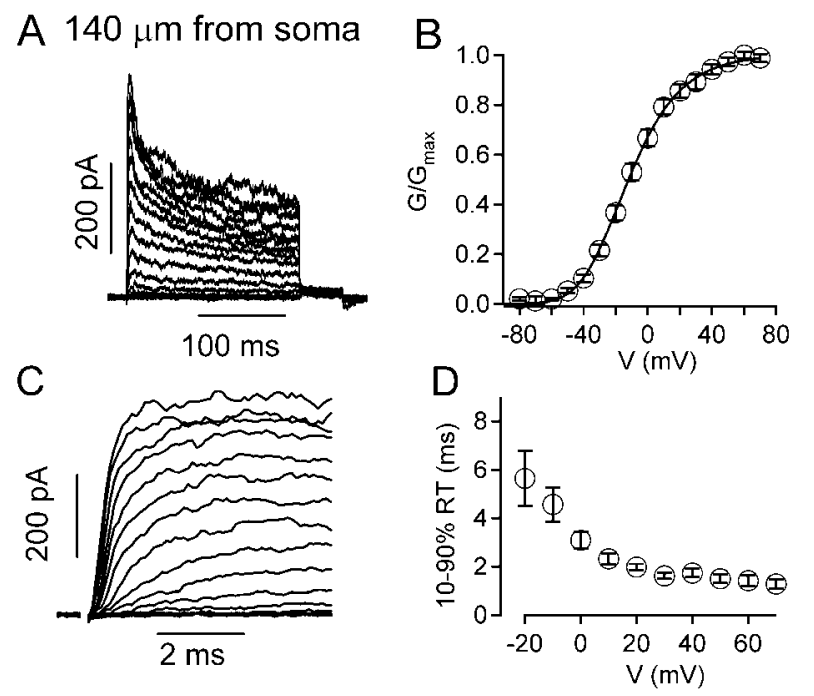

Figure 1. Voltage dependence and kinetics of activation of dendritic potassium currents. $A$, Potassium currents elicited in an outside-out patch taken from a Purkinje cell dendrite $(140 \mu \mathrm{m}$ from the soma) by $200 \mathrm{msec}$ steps from a holding potential of $-90 \mathrm{mV}$ to voltages from -80 to $70 \mathrm{mV}$ (10 mV intervals). B, Peak conductance-voltage relationship for dendritic patches (mean \pm SEM; 16 cells). Conductance was calculated assuming a reversal potential of $-95 \mathrm{mV}$ and a linear current-voltage curve for open channels. The solid curve is given by Boltzmann function raised to the fourth power: $\left[1 /\left(1+\exp \left[-\left(V-V_{h}\right) / k\right]\right)\right]{ }^{4}$, where $V$ is the membrane potential, $V_{h}$ is the potential at which the Boltzmann function is 0.5 , and $k$ is the slope factor. $V_{h}$ is $-46 \mathrm{mV}$, and the slope factor is $20 \mathrm{mV}$. This function reaches a midpoint at a value of $V_{h}+$ $1.67 * k$, or $-13 \mathrm{mV}$. C, Time course of activation at higher time resolution. $D$, Time for current to rise from 10 to $90 \%$ of its peak value plotted against test pulse voltage for 16 dendritic patches. These parameters are fits to the averaged data. Table 1 shows the values for midpoint, $k$, and noninactivating fraction obtained by averaging fits to data from individual patches.

following secondary antibodies: Alexa 488 goat anti-mouse (1:100; Molecular Probes, Eugene, OR) and Rhodamine Red-X goat anti-rabbit (1:100; Jackson ImmunoResearch Labs) for $1 \mathrm{hr}$ at room temperature in TNB. Subsequently, sections were washed once in TNT and twice in PBS (10 min each) and then coverslipped in Vectashield mounting medium (Vector Laboratories, Burlingame, CA). Sections were photographed using a confocal microscope (Bio-Rad MRC-1024 with 20, 40, or $60 \times$ objectives; Bio-Rad, Hercules, CA). Images were merged using Adobe Photoshop 5.5 (Adobe Systems, San Jose, CA).

In all experiments, control experiments were performed by preincubating sections (taken adjacent to the test sections) with the primary anti-Kv3.4 or anti-Kv3.3 antibodies in the presence of a large molar excess of peptide antigen. For all images shown, adjacent sections treated with an excess of peptide antigen had only faint nonspecific staining when processed identically.

\section{Results}

\section{Voltage dependence and kinetics of dendritic} potassium current

We characterized the voltage dependence and kinetics of voltageactivated potassium current in outside-out patch recordings taken from Purkinje cell dendrites $\leq 250 \mu \mathrm{m}$ from the soma. All patches had detectable voltage-activated potassium current, and most had currents of several hundred picoamperes. Figure $1 \mathrm{~A}$ shows a typical family of currents recorded from a patch taken from a Purkinje cell dendrite $140 \mu \mathrm{m}$ from the soma. Figure $1 B$ shows peak conductance as a function of voltage for collected data from 16 patches formed at dendritic locations $>100 \mu \mathrm{m}$ from the soma. Currents required relatively strong depolarizations to activate, with half-maximal activation at $-10 \pm 2 \mathrm{mV}$ $(n=16)$. The conductance versus voltage curve was well fit by a
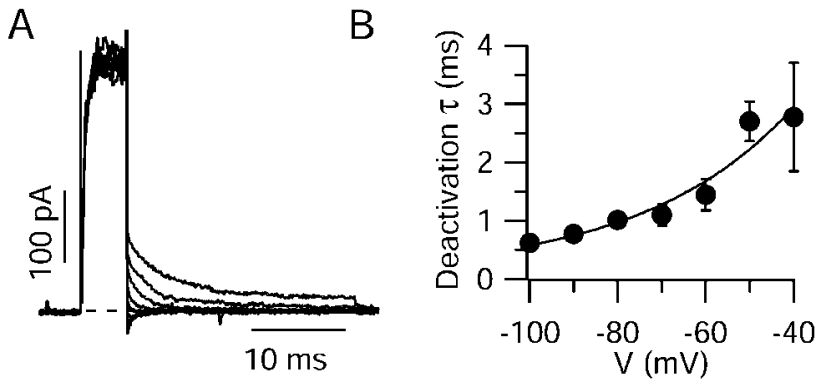

Figure 2. Rapid deactivation of dendritic potassium currents. $A$, Potassium currents elicited in a dendritic outside-out patch (taken from dendrite $120 \mu \mathrm{m}$ from soma) with a $5 \mathrm{msec}$ step to $70 \mathrm{mV}$ to fully activate the channels followed by repolarization to voltages from -110 to -40 $\mathrm{mV}$ in $10 \mathrm{mV}$ increments. Tail currents reversed between -80 and $-90 \mathrm{mV}$. B, Collected data (mean $\pm \mathrm{SEM}$ ) from four dendritic patches. Protocols were as in $A$, except that both shorter ( 5 $\mathrm{msec}$ ) and longer (100 msec) activating steps to $70 \mathrm{mV}$ were used. With the longer activating pulses, the reversal potential of tail currents was approximately $-50 \mathrm{mV}$, probably reflecting accumulation of potassium ions on the external surface of the patch. This facilitated the measurement of time constants at -80 and $-90 \mathrm{mV}$. Time constants did not depend on the length of the activation pulse or the direction of current flow.

Boltzmann function raised to the fourth power, with a slope factor of $23 \pm 1 \mathrm{mV}$.

Activation was rapid (Fig. 1C), with a $10-90 \%$ rise-time of $3.1 \pm 0.4 \mathrm{msec}$ at $0 \mathrm{mV}(n=16)$ (Fig. $1 D)$. Activation kinetics were strongly voltage dependent, and rise-times decreased to near $1 \mathrm{msec}$ for depolarizations positive to $40 \mathrm{mV}$. Deactivation of the current was also very fast (Fig. 2). Deactivation could generally be fit well by a single exponential, with average time constants of $2.8 \pm 0.9 \mathrm{msec}$ at $-40 \mathrm{mV}$ and $1.1 \pm 0.2 \mathrm{msec}$ at -70 $\mathrm{mV}(n=4)$.

Dendritic potassium currents showed partial inactivation, typically decaying by $30-50 \%$ over $200 \mathrm{msec}$ for voltage steps positive to $0 \mathrm{mV}$. The time course of decay could generally be fit well by two exponential functions (Fig. 3A). Measured for maximal activation by steps to $70 \mathrm{mV}$, the faster time constant had an average value of $19 \pm 3 \mathrm{msec}(n=26)$ and the slower time constant was $377 \pm 131 \mathrm{msec}$. On average, the fast inactivating component contributed $24 \pm 4 \%$ of the total peak current, the slow-inactivating component contributed $31 \pm 6 \%$, and $45 \pm 5 \%$ remained after $200 \mathrm{msec}$. Figure 3, $B$ and $C$, shows the steadystate voltage dependence of inactivation, determined by changing the holding potential for $5 \mathrm{sec}$ before a $100 \mathrm{msec}$ test pulse to 70 $\mathrm{mV}$. A notable feature is that inactivation becomes substantial only when depolarizations reach voltages at which significant current is activated (positive to $-40 \mathrm{mV}$ ). This property differentiates these currents from A-type potassium currents mediated either by Kv4 or Kv1.4 (Pak et al., 1991; Rettig et al., 1992) channels, which inactivate strongly at subthreshold voltages.

When the voltage dependence of the inactivation of dendritic currents by a $5 \mathrm{sec}$ prepulse was fit with a Boltzmann function plus a constant, the average midpoint was $-37.6 \pm 4.5 \mathrm{mV}$, and the slope factor was $12 \pm 0.6 \mathrm{mV}(n=6)$. Inactivation was nearly complete with depolarizations beyond approximately $-20 \mathrm{mV}$.

We also determined the voltage dependence of inactivation using 100 msec prepulses, which approximate the time scale of complex spikes and short plateau potentials that dendrites may experience. In this case, inactivation was only partial ( $35-40 \%)$ even for depolarizations up to $10 \mathrm{mV}$ (Fig. 3C, open circles). The midpoint of inactivation determined using $100 \mathrm{msec}$ prepulses was $-33.3 \pm 3 \mathrm{mV}$, and the slope factor was $11.3 \pm 3.4 \mathrm{mV}$, with an average fraction of $58 \pm 6 \%(n=10)$ remaining noninacti- 

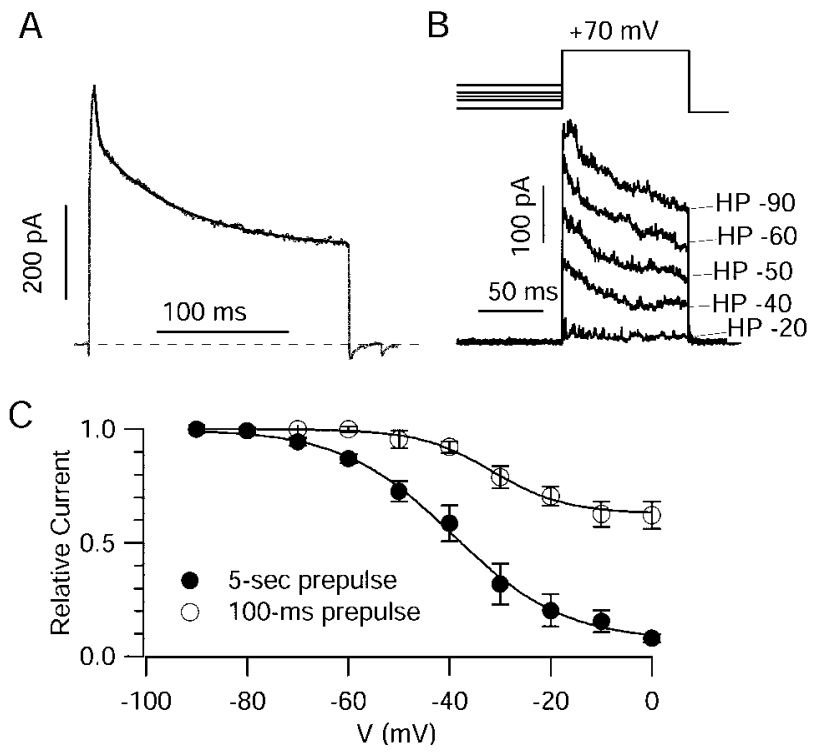

Figure 3. Voltage dependence and kinetics of inactivation of potassium current in dendritic patches. $A$, Potassium current elicited by a $200 \mathrm{msec}$ pulse from -90 to $70 \mathrm{mV}$ in a dendritic outside-out patch taken $140 \mu \mathrm{m}$ from the soma. Inactivation could be fit by two exponentials plus a constant, and the experimental trace is overlaid by a fitted curve with $18 \%$ of the current decaying with a time constant of $2.5 \mathrm{msec}, 43 \%$ with a time constant of $68 \mathrm{msec}$, and $39 \%$ nondecaying. $B$, Voltage dependence of inactivation determined by changing the holding potential for $5 \mathrm{sec}$ before a test pulse to $70 \mathrm{mV}$ (patch taken $70 \mu \mathrm{m}$ from the soma). C, Peak test pulse current versus prepulse voltage for prepulses of 5 sec (filled circles; mean \pm SEM; $n=6$ ) or 100 msec (open circles; mean \pm SEM; $n=10$ ). Average values are fit by a Boltzmann function decaying to a non-zero fraction, $\mathrm{NI}+(1-\mathrm{NI}) /\left(1+\exp \left[\left(V-V_{h}\right) / k\right]\right)$, where $\mathrm{Nl}$ is the fraction of noninactivating current, $V_{h}$ is the midpoint for the inactivating fraction, and $k$ is the slope factor for the inactivating fraction. For 5 sec prepulses, $V_{h}=-39 \mathrm{mV}, k=11.0 \mathrm{mV}$, and $\mathrm{NI}=0.07$. For $100 \mathrm{msec}$ prepulses, $V_{h}=-32 \mathrm{mV}, k=7.3 \mathrm{mV}$, and $\mathrm{NI}=0.63$. These parameters are for fits to the averaged data. Table 1 shows the values for $V_{h}, k$, and noninactivating fraction obtained by averaging fits to data from individual patches.

vated. Interestingly, there was considerable heterogeneity among individual dendritic patches in the susceptibility to inactivation by $100 \mathrm{msec}$ prepulses, ranging from 20 to $70 \%$ of the total current.

\section{Comparison with somatic currents}

Figure 4 illustrates how the current magnitude and degree of inactivation depend on the distance from the soma. Outside-out patches were taken at positions varying from the soma itself to the distal dendrites. Overall, currents in somatic patches (Fig. 4A) were very similar to those in dendritic patches (Table 1). Their voltage dependence was very similar, with half-maximal activation at $-12 \pm 2 \mathrm{mV}(n=18)$ and a slope factor of $18 \pm 2 \mathrm{mV}$ when fit by a Boltzmann function to the fourth power (Fig. $4 \mathrm{~B}$ ). As for dendritic currents, somatic currents had rapid activation and deactivation kinetics (Table 1). However, there were two trends evident when examining currents as a function of distance from the soma. On average, currents were somewhat smaller with increasing distance from the soma (Fig. 4C). The average current amplitude for a step from -90 to $70 \mathrm{mV}$ was $779 \pm 130 \mathrm{pA}$ in somatic patches ( 25 patches), $440 \pm 46$ for dendrites $\leq 100 \mu \mathrm{m}$ from the soma (70 patches), and $361 \pm 54 \mathrm{pA}$ for dendrites at distances $>100 \mu \mathrm{m}$ ( 28 patches). There was a high degree of variability in the size of potassium currents from individual patches from both soma and dendrites, suggesting a nonuniform patchy distribution of channels in both areas (some variability may also reflect patch sizes, although to minimize this, patches
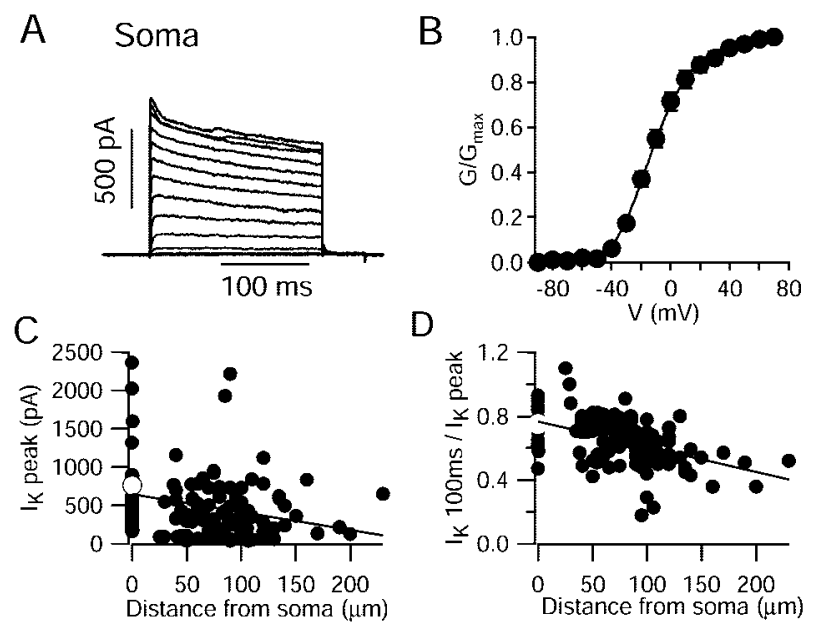

Figure 4. Dependence of potassium current amplitude and degree of inactivation on distance from soma. A, Potassium currents elicited in a somatic patch by $200 \mathrm{msec}$ steps from a holding potential of $-90 \mathrm{mV}$ to voltages from -80 to $70 \mathrm{mV}$ (10 mV intervals). B, Peak conductance-voltage relationship for somatic patches (mean \pm SEM; 18 cells). Conductance was calculated assuming a reversal potential of $-95 \mathrm{mV}$ and a linear current-voltage curve for open channels. Solid curve is a Boltzmann function raised to the fourth power, with a midpoint potential of $-11.5 \mathrm{mV}$ and slope factor $18 \mathrm{mV}$. C, Magnitude of peak potassium current (step from -90 to $70 \mathrm{mV}$ ) in outside-out patches, plotted as a function of distance from the soma from which the patch was formed (closed circles). To facilitate the comparison, only data obtained with 7-11 M $\Omega$ pipettes are plotted. The white symbol indicates mean \pm SEM for patches from the cell body with the same range of electrode resistances. The solid line is leastsquares to the data and has an $x$-intercept of $652 \mathrm{pA}$ and slope of $-2.3 \mathrm{pA} / \mu \mathrm{m}$. $D$, The ratio of the current remaining after $100 \mathrm{msec}$ to the peak current is plotted versus distance from soma (closed circles). Steps were to $70 \mathrm{mV}$. The white symbol indicates mean \pm SEM for patches from the cell body. Solid line is least-squares to the data and has an $x$-intercept of 0.77 and slope of $-0.0016 \mu \mathrm{m}^{-1}$.

were included in the statistics only for pipette resistances between 7 and $11 \mathrm{M} \Omega$ ).

There was also a trend evident in the degree of inactivation with distance from the soma (Fig. $4 D$ ), with inactivation being more pronounced with increasing distance from the soma. For depolarizations to $70 \mathrm{mV}$, the ratio of noninactivating current (measured after $100 \mathrm{msec}$ ) to peak current decreased from $0.75 \pm$ $0.02(n=28)$ for somatic patches to $0.67 \pm 0.02(n=71)$ for dendrites $\leq 100 \mu \mathrm{m}$ from the soma and to $0.55 \pm 0.02(n=28)$ for distal dendrites ( $>100 \mu \mathrm{m}$ from the soma). Interestingly, although somatic currents on average inactivated less completely during $100 \mathrm{msec}$ or $200 \mathrm{msec}$ pulses, the value of the fast inactivation time constant was similar to that of dendritic patches. Moreover, the parameters of the steady-state inactivation curve obtained using a 5 sec prepulse were very similar for somatic and dendritic currents (Table 1).

\section{Sensitivity to TEA and 4-aminopyridine}

The potassium currents in dendritic membranes were highly sensitive to block by external TEA (Fig. 5A). At $0.1 \mathrm{~mm}$, TEA blocked the current by $46 \pm 4 \%$, and $1 \mathrm{mM}$ TEA blocked $76 \pm 4 \%$ of the current. The dose-response curve (Fig. $5 B$ ) suggested that $\sim 80 \%$ of the total potassium current is highly sensitive to TEA with a half-blocking concentration of $\sim 100 \mu \mathrm{M}$ for this component. There also appears to be a component of current ( $\sim 20 \%$ of the whole) with much lower sensitivity to TEA, being only partly blocked by $10 \mathrm{~mm}$.

It has been found previously that somatic potassium currents in mouse Purkinje neurons are effectively blocked by external TEA (Raman and Bean, 1999; Southan and Robertson, 2000) 

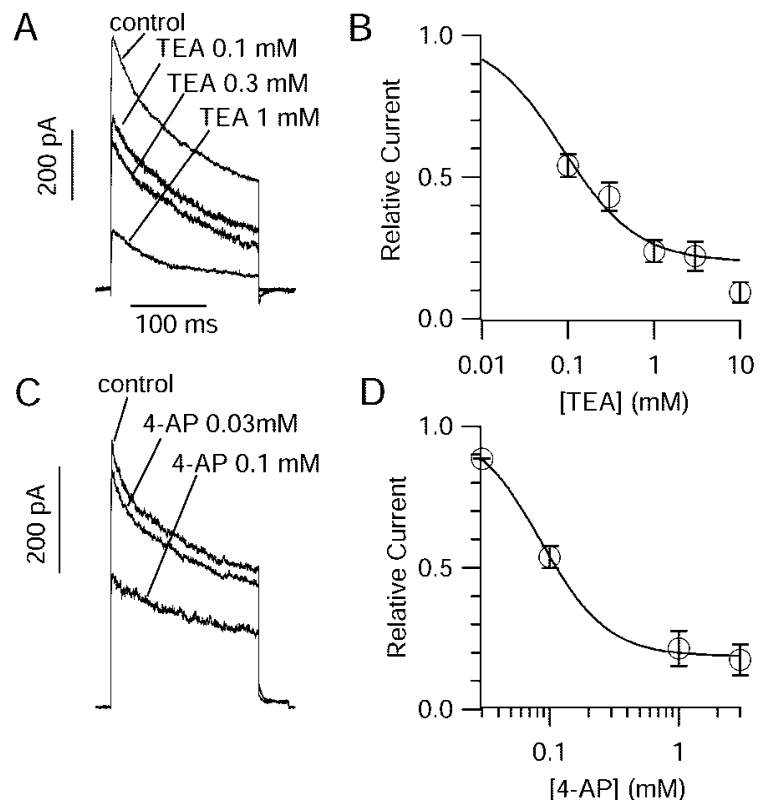

Figure 5. Pharmacology of dendritic potassium currents. $A$, Effects of increasing concentrations of external TEA on currents evoked by $200 \mathrm{msec}$ pulses from -90 to $70 \mathrm{mV}$ in a dendritic patch (excised 50 microns from soma). B, Dose-response curve for block of dendritic current by external TEA. The solid curve represents fit by the logistic equation to the data up to $3 \mathrm{~mm}$ TEA, $0.8 /\left[1+(\mathrm{TEA}) / K_{\mathrm{d}}\right]+0.2$, with $K_{\mathrm{d}}=85 \mu \mathrm{M}$. C, Effect of 4-AP on currents from a dendritic outside-out patch (excised 75 microns from soma). D, Dose-response curve for block of dendritic current by 4-AP. The solid curve represents fit by the logistic equation with variable slope (Hill coefficient) given by $0.81 /\left(1+\left[(4-\mathrm{AP}) / K_{\mathrm{d}}\right]^{\mathrm{n}}\right)+0.19$, with $K_{\mathrm{d}}=86 \mu \mathrm{m}$ and $n=1.7$.

with a half-blocking concentration of $120 \mu \mathrm{M}$ for somatic currents in outside-out patches (Southan and Robertson, 2000). In agreement, we found that $1 \mathrm{~mm}$ external TEA blocked $79 \pm 3 \%$ $(n=9)$ of the total potassium current in patches taken from the somata of rat Purkinje neurons (data not shown), which was almost identical to the sensitivity of rat dendritic channels under the same conditions ( $76 \pm 4 \%$ block by $1 \mathrm{~mm}$ TEA). Thus, both dendritic and somatic potassium currents have a predominant component that is highly sensitive to external TEA.

The potassium currents in the dendrites were also highly sensitive to 4-AP. At $100 \mu \mathrm{M}, 4$-AP blocked approximately half the total current (Fig. 5C). The dose-response curve (Fig. 5D) suggests that a component of the total current comprising $\sim 80 \%$ is highly sensitive to 4 -AP with a half-blocking concentration of 86 $\mu \mathrm{M}$. The high sensitivity of most of the dendritic potassium current to 4-AP in rat neurons is very similar to previous results with somatic potassium current in mouse Purkinje neurons, in which 4-AP acted with a half-blocking concentration of $133 \mu \mathrm{M}$ (Southan and Robertson, 2000). In our experiments, $\sim 20 \%$ of the current was resistant even to high concentrations of 4-AP with little additional effect of $3 \mathrm{~mm} 4$-AP compared with $1 \mathrm{~mm}$; this is slightly different from somatic currents in mouse neurons, in which virtually all current was blocked by $5 \mathrm{~mm}$ 4-AP (Southan and Robertson, 2000).

The high sensitivity to 4 -AP of the potassium current in outside-out patches from rat dendritic membrane is nicely consistent with previous current-clamp recordings from dendrites of guinea-pig Purkinje neurons, in which outward rectification was reduced by low concentrations of 4-AP (Etzion and Grossman, 2001).

\section{Immunocytochemistry}

These results show that the predominant potassium current in the dendritic membrane of Purkinje cells requires relatively large depolarizations to be activated and has rapid activation and deactivation kinetics as well as high sensitivity to both external TEA and 4-AP. These properties are all characteristic of members of the Kv3 family (Martina et al., 1998; Rudy and McBain, 2001; Lien et al., 2002). We therefore used immunocytochemistry to test whether particular members of the Kv3 family of subunits are present in the dendrites of Purkinje neurons. We found clear staining for both Kv3.3 and Kv3.4 subunits (Fig. 6). With antibodies to both subunits, staining was present both in cell bodies and throughout the dendritic tree. With Kv3.3 antibodies, there was prominent staining of both cell bodies and dendrites (Fig. $6 A-C)$, suggesting that Kv3.3 subunits are highly expressed in both compartments. Staining of cell bodies and proximal dendrites was especially strong. The same results were obtained in four different slices from three different animals. Antibodies to Kv3.4 subunits also stained both cell bodies and dendrites (Fig. $6 D-G)$; however, staining generally appeared stronger in the dendrites than in the cell bodies, and there were often segments of distal dendrites that showed very strong staining (Fig. $6 \mathrm{H}$, arrow). The same results were obtained in six different slices from three different animals.

\section{Activation by action potentials and synaptic potentials}

Under what conditions are dendritic potassium channels activated, and what is their functional role? To explore these questions, we made current-clamp recordings of the voltage trajectory of dendritic membrane under various circumstances and then performed voltage-clamp experiments to examine whether those voltage patterns activated dendritic potassium currents in outside-out patches, often formed using the same pipette used to make the current-clamp recordings. Purkinje neurons often fire spontaneous action potentials in a highly regular manner (Häusser and Clark, 1997), and in cerebellar slices, spontaneous firing becomes faster and more regular when ongoing basal synaptic activity is blocked (Häusser and Clark, 1997). Figure 7A shows how the action potential height of spontaneous action potentials changed with distance from the soma in our experiments. The inset in Figure 7 shows a typical example in which simultaneous current-clamp recordings were made in the cell body and dendrite (in this case, at a distance of $60 \mu \mathrm{m}$ ). The spontaneous spikes in the cell body had amplitude of $56 \mathrm{mV}$, whereas those measured in the dendrite $60 \mu \mathrm{m}$ away had an amplitude of $37 \mathrm{mV}$. Collected results are shown in Figure $7 A$; the decline with a distance of spontaneous action potentials is very similar to that observed previously by Stuart and Häusser (1994) and Pouille et al. (2000) for action potentials elicited by current injection. The data show that within $\sim 70-80 \mu \mathrm{m}$ of the soma, spontaneous spikes commonly have peaks positive to $-40 \mathrm{mV}$, the voltage at which activation of dendritic potassium current becomes substantial. Thus, at least for the proximal dendrite, there is the potential for dendritic potassium channels to be activated during spontaneous action potentials.

However, it is also necessary to establish that activation of the dendritic channels is sufficiently rapid to be activated during the action potential in the dendrite, especially because action potentials in Purkinje neurons are very narrow $(0.53 \pm 0.02 \mathrm{msec}$; half-height width; measured in the soma; $23^{\circ} \mathrm{C} ; n=14$ cells). The experiment in Figure $7 B$ shows directly that dendritic potassium channels are activated by the action potentials they experience. In this experiment, the recording pipette was first used to make a 
A anti-Kv3.3

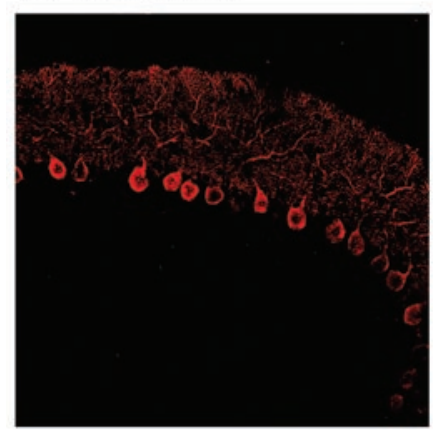

E anti-Kv3.4

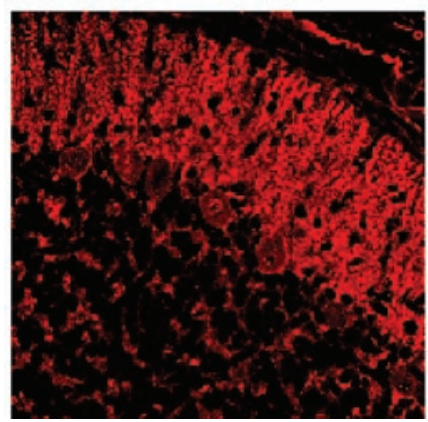

anti-Calbindin

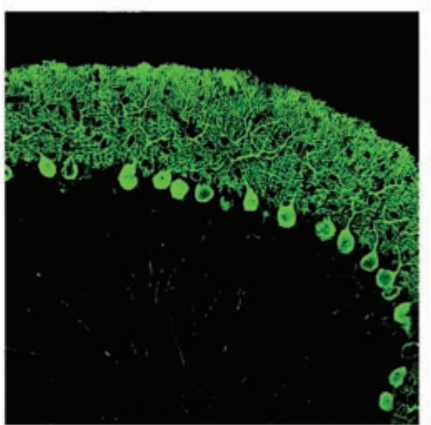

$\mathrm{F}$ anti-Calbindin

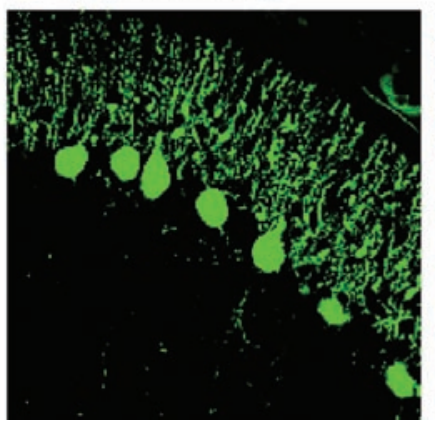

C merged

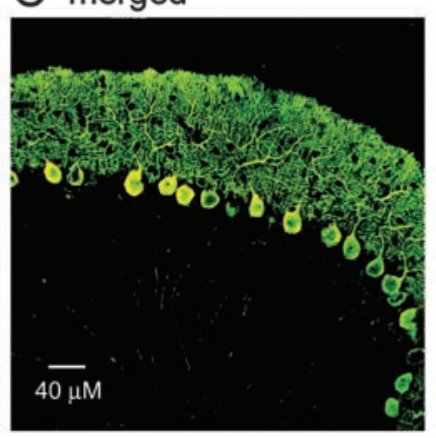

G merged

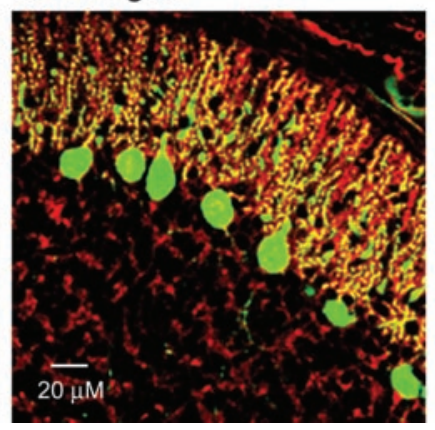

D



$\mathrm{H}$

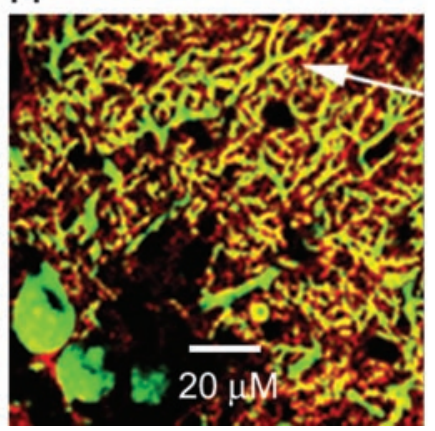

Figure 6. Immunostaining for Kv3.3 and Kv3.4 subunits in somata and dendrites of Purkinje neurons. A, Confocal image of Purkinje cell layer after staining with antibodies to Kv3.3 (red). B, Same slice stained using primary antibodies to calbindin (green). C, Merged image. D, Higher magnification merged image of staining by Kv3.3 (red) and calbindin (green). E-G, Staining with antibodies to Kv3.4 (E, red), calbindin ( $F$, green), and merged image ( $G$ ).H, Higher magnification merged image of staining by Kv3.4 (red) and calbindin (green). Note the colocalization of the antibodies in many regions of distal dendrites (including that marked by an arrow). For both Kv3.3 and Kv3.4 staining, controls were run by staining adjacent sections and processing them in parallel except that the antibodies were preincubated with 100-fold excess of antigenic peptide; there was only very faint nonspecific staining of cell body cytoplasm present in the controls.

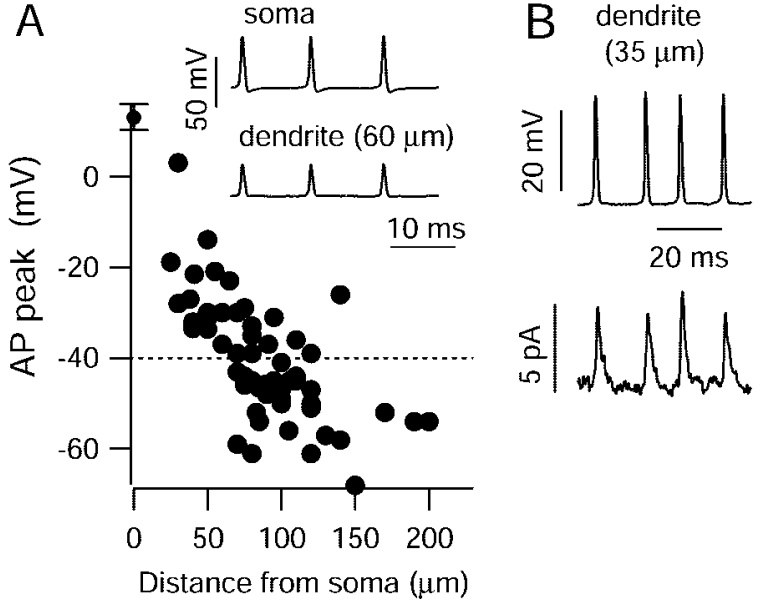

Figure 7. Activation of dendritic potassium current by truncated dendritic spikes. A, Peak amplitude of dendritic action potentials (from spontaneous firing of neurons with no injected current) plotted against distance from soma. The dashed line represents the average voltage at which dendritic $\mathrm{K}^{+}$currents activate by $\sim 10 \%$. Inset, voltage traces of spontaneous activity obtained recording simultaneously from soma and dendrite of a Purkinje neuron. $B$, Voltage traces recorded from another dendrite (top); the recordings used as voltage command activated potassium currents in the outside-out patch obtained from the same dendrite.

current-clamp recording from the dendrite (at $35 \mu \mathrm{m}$ from the soma), and spontaneous spikes with amplitude of $\sim 35 \mathrm{mV}$ (occurring at a frequency of $\sim 50 \mathrm{~Hz}$ ) were recorded (top trace). The dendritic pipette was then detached to form an outside-out patch, and we tested whether the previously recorded segment of spontaneous activity used as command voltage could activate the potassium channels in the patch. There was substantial activation during the spikes. In this patch, peak current activated by a step to $70 \mathrm{mV}$ was $170 \mathrm{pA}$; thus, expressed in terms of conductance and assuming a reversal potential of $-95 \mathrm{mV}$, the current of $\sim 5 \mathrm{pA}$ elicited at the peaks of the dendritic action potentials $(-10 \mathrm{mV})$ represents $\sim 6 \%$ of the maximal conductance when the channels are fully activated. In three experiments with patches taken from distances between 35 and $60 \mu \mathrm{m}$ from the soma, dendritic spikes activated $8 \pm 3 \%$ of the maximal potassium conductance in the patch.

Activation of potassium current by the spikes in the proximal dendrite would be predicted to actively dampen the dendritic spike beyond the truncation from the passive properties of the dendrite. The high sensitivity of the dendritic potassium channels to external TEA provides a way of testing this prediction. Figure 8 shows such an experiment in which a prerecorded waveform taken from current-clamp stimulation of a Purkinje neuron cell body was applied as a voltage-clamp command at the cell body. A second electrode recorded the voltage response at a dendritic location $35 \mu \mathrm{m}$ away with 300 nM TTX present in the external solution to prevent spontaneous firing of the neuron and avoid eliciting uncontrolled sodium currents in the cell body. As expected, the voltage recorded at the dendrite (height, $35 \mathrm{mV}$ ) was much smaller than that at the cell body $(94 \mathrm{mV})$. When $1 \mathrm{~mm}$ TEA was added to the external solution, the spikes measured at the dendrite became larger and also broader. This suggests that dendritic potassium channels have the effect of both truncating and narrowing the dendritic spike, at least in the proximal dendrite. In collected data from three cells, the half-duration of dendritic 


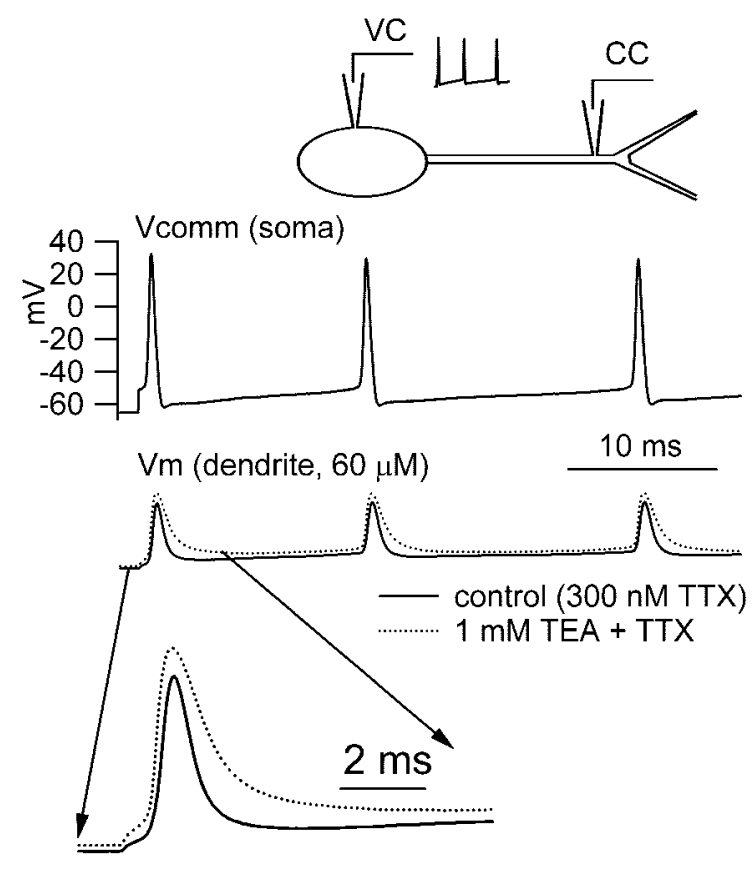

Figure 8. Dendritic potassium channels actively depress and narrow sodium spikes in the dendrite. $A$, A double recording was performed from soma and dendrite of a Purkinje neuron in the presence of $300 \mathrm{~nm}$ TTX. The soma was voltage clamped with a trace of Purkinje neuron spontaneous activity $(A)$. The dendritic pipette recorded in current-clamp passively spread action potential either in control condition or after bath application of $1 \mathrm{~mm}$ TEA (B).C, The first action potential in the train (area indicated by arrows) shown on an expanded scale. Note the large increase in spike duration and the incomplete repolarization induced by TEA.

spikes increased from $0.66 \pm 0.03 \mathrm{msec}$ in control to $0.87 \pm$ $0.03 \mathrm{msec}$ after block of potassium currents by $1 \mathrm{mM}$ TEA.

Purkinje neurons receive excitatory synaptic input from the inferior olive by means of climbing fibers, which form powerful 1:1 synaptic connections with Purkinje neurons. Stimulation of a single climbing fiber evokes a large, all-or-none EPSP on which multiple action potentials are superimposed, the "complex spike" (Eccles et al., 1966). Complex spikes probably represent complicated interaction of synaptic currents with intrinsic membrane properties of both dendrites and cell body (Llinás and Sugimori, 1980; Callaway and Ross, 1997; Pouille et al., 2000; Cavelier et al., 2002). The superimposed fast spikes originate in the soma (Stuart and Häusser, 1994) and are not evident in dendrites more distal than $70 \mu \mathrm{m}$ or so. However, the underlying maintained depolarization can have a magnitude of 40-50 $\mathrm{mV}$ even in distal dendrites (Stuart and Häusser, 1994; Callaway and Ross, 1997). Figure 9 shows the response to climbing fiber stimulation measured in a dendrite $75 \mu \mathrm{m}$ from the soma with the depolarization reaching nearly $-30 \mathrm{mV}$. When the recording electrode was pulled away to form an outside-out patch and the patch was stimulated by the recorded waveform, there was a substantial potassium current ( $33 \mathrm{pA}$ ) elicited, which reached a peak a few milliseconds later than the peak of the voltage response. In this patch, the peak current activated by a step to $70 \mathrm{mV}$ was $670 \mathrm{pA}$, and the current during the climbing fiber response corresponded to $\sim 15 \%$ of the maximal available potassium conductance. This experiment makes it clear that substantial dendritic potassium currents are activated during climbing fiber responses and shows that they must influence the duration and shape of the response. This experiment was performed in the dendrites of five different neurons, at distances ranging from 45 to $85 \mu \mathrm{m}$ times (four using the climbing fiber response of each cell as voltage command and

\section{A Dendritic climbing fiber response}

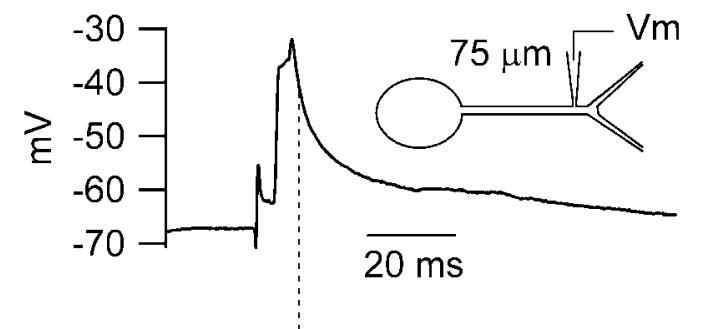

\section{B Elicited $\mathrm{K}$ current in o-o patch}

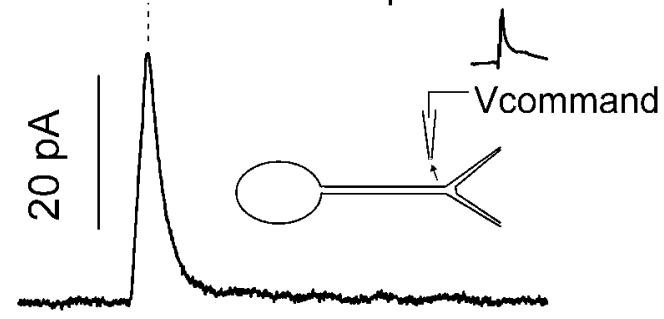

Figure 9. Activation of dendritic potassium current by climbing fiber response. $A$, Voltage response to climbing fiber stimulation recorded in a dendrite at $75 \mu \mathrm{m}$ from the soma. $B$, After forming an outside-out patch using the same pipette at the same location, the recorded voltage response was used as voltage command to record the potassium current elicited in the dendrite by the EPSP.

one using the responses from another cell). The peak of the climbing fiber EPSP varied from -35 to $-24 \mathrm{mV}$, and the average potassium conductance activated by the EPSP as waveform was $8 \pm 4 \%$ of the conductance activated by a step from -90 to 70 $\mathrm{mV}$.

\section{Discussion}

Molecular composition of dendritic potassium channels

The predominant potassium currents in outside-out patches from Purkinje cell dendrites had rapid activation and deactivation kinetics and high sensitivity to external TEA and 4-AP, consistent with Kv3 family potassium channels (Grissmer et al., 1994; Martina et al., 1998; Rudy and McBain, 2001; Lien et al., 2002). In concordance, the immunocytochemical experiments show the presence of Kv3.4 and Kv3.3 protein in both dendrites and somata of Purkinje neurons. Previously, Kv3 family channels were most commonly found localized in somata, axons, and presynaptic terminals of neurons (Rudy and McBain, 2001), but dendritic Kv3.3 subunits have been described in Purkinje cells of an apteronid fish (Rashid et al., 2001), consistent with our results. The presence of Kv3.3 subunits is consistent with previous in situ labeling for Kv3.3 mRNA in mouse Purkinje neurons (GoldmanWohl et al., 1994).

Our results showing prominent staining for Kv3.4 protein in Purkinje neurons differs from a previous study (Veh et al., 1995; Laube et al., 1996). The antibodies used for this previous work were raised against a region in the $\mathrm{C}$ terminus of the Kv3.4a protein that is $\sim 25 \%$ different in the Kv3.4c splice variant (Veh et al., 1995; Vullhorst et al., 2001), whereas the antibodies that we used were raised to a region (residues 177-195 of the N-terminal region) that is conserved between $\mathrm{Kv} 3.4 \mathrm{a}$ and $\mathrm{Kv} 3.4 \mathrm{c}$ proteins. It is possible that $\mathrm{Kv} 3.4 \mathrm{c}$ subunit expression is higher than that of Kv3.4a subunits or is more easily detected by antibodies.

Kv3.1 RNA is present at low levels of expression in Purkinje neurons (Weiser et al., 1994), and expression declines dramatically between P10 and P17 (M. K. Jarvinen, M. Fry, D. M. Porter, 
and R. A. Maue, personal communication). Consistent with this, we found that antibodies to Kv3.1b protein produced no detectable staining of either Purkinje cell dendrites or somata in P15P16 rats while robustly staining hippocampal neurons (G. L. Yao, unpublished data), consistent with previous results (Weiser et al., 1995).

Different Kv3 family subunits have different kinetic properties. Homomers of Kv3.3 subunits inactivate slowly (hundreds of milliseconds) (Rudy and McBain, 2001). Kv3.4a homomeric channels inactivate rapidly (tens of milliseconds) and completely (Rettig et al., 1992; Diochot et al., 1998; Rudy and McBain, 2001), and Kv3.4c channels inactivate more slowly and less completely than Kv3.4a channels (G. Baranauskas, T. Tkatch, and D. J. Surmeier, personal communication). Kv3 family heteromers have been shown to form in heterologous expression systems (Weiser et al., 1994; Rudy and McBain, 2001) and mediate currents with kinetic properties intermediate between the component subunits. Thus, the components of dendritic current with different inactivation kinetics might represent channels formed by different mixtures of Kv3.3, Kv3.4a, and Kv3.4c subunits, perhaps with other Kv3 family subunits as well.

Approximately $20 \%$ of the current in dendritic patches was left unblocked by $3 \mathrm{~mm}$ TEA or $3 \mathrm{~mm} 4$-AP. Additional analysis will be required to identify the channels underlying this component. Sacco and Tempia (2002) have described a TEA-resistant A-type potassium current in whole-cell recording from mouse Purkinje neurons much younger (3-9 d old) than the rat Purkinje neurons we studied (14-21 d old); the TEA-resistant current comprised approximately one-third of the total in their experiments, suggesting developmental changes in contributions from different potassium channels (cf. Yool et al., 1988).

\section{Comparison with somatic potassium channels}

Channels in somatic patches had very similar voltage dependence, kinetics, and pharmacology as dendritic channels (Table 1). Our results for somatic potassium channels are very similar to those obtained previously in the somata of mouse Purkinje neurons (Raman and Bean, 1999; Southan and Robertson, 2000). Together, these results suggest that the predominant voltageactivated potassium channels in the cell bodies of Purkinje neurons are also of the Kv3 family, and our immunocytochemical results show staining of both Kv3.3 and Kv3.4 subunits in the somata as well as dendrites of Purkinje neurons.

Purkinje neurons are known to possess both SK-type and BKtype calcium-activated potassium channels (Yool et al., 1988; Gähwiler and Llano, 1989; Gruol et al., 1991; Jacquin and Gruol, 1999; Cingolani et al., 2002; Womack and Khodakhah, 2002a, 2003; Edgerton and Reinhart, 2003), and there is some evidence that these channels are expressed to at least some extent in dendrites (Gruol et al., 1991; Cingolani et al., 2002; Womack and Khodakhah, 2003). There was usually no sign of calciumactivated current in our recordings; calcium channel activity was apparently not maintained in the patches, because we never saw inward calcium currents. Only very seldom, and for strong depolarizations $(\mathrm{Vm},>20 \mathrm{mV}$ ), did we observe individual openings of large conductance channels resembling the BK type of calciumdependent potassium channels. The characterization of calcium-activated potassium channels in Purkinje cell dendrites may require different experimental approaches (Womack and Khodakhah, 2002a).

\section{Functional significance}

Unlike many other types of neurons, sodium-dependent action potentials are not effectively propagated in the dendrites of Purkinje neurons because dendritic sodium-channel density is low (Stuart and Häusser, 1994). It is therefore somewhat unexpected to find strong dendritic expression of Kv3 family potassium channels whose high threshold and rapid activation are most obviously suited to give rapid repolarization of large, narrow action potentials in fast-spiking cells. Despite the absence of backpropagating sodium spikes, the density of voltage-activated potassium current in Purkinje cell dendrites is similar or higher than in several cell types in which sodium action potentials do actively propagate into dendrites (Hoffman et al., 1997; Bekkers, 2000; Korngreen and Sakmann, 2000; Martina et al., 2000). Our results suggest that one functional role of these channels is to help quickly damp even the passive propagation of action potentials into the dendritic tree (cf. Roth and Häusser, 2001). Crucial for this function is the rapid activation kinetics of dendritic currents, even at voltages at the foot of the activation curve.

The inactivation properties of Kv3 channels of Purkinje cell dendrites differ considerably from the inactivation of potassium current in dendrites of pyramidal neurons, which is primarily attributable to Kv4 family channels (Maletic-Savatic et al., 1995; Hoffman et al., 1997; Hoffman and Johnston, 1998). The midpoint of inactivation for the inactivating component of dendritic channels in Purkinje neurons $(-38 \mathrm{mV})$ is much more positive than that in dendrites of pyramidal neurons $(-56 \mathrm{mV})$ (Hoffman and Johnston, 1998). The channels in pyramidal neuron dendrites would be almost completely inactivated at the more depolarized voltages typical of spontaneously firing Purkinje neurons, whereas the Kv3 channels are still available.

Our results with climbing fiber stimulation show that climbing fiber EPSPs are large enough to activate potassium channels, even in fairly distal dendrites, so that the presence of the channels will help determine the magnitude and duration of such EPSPs. Distal dendrites are also known to support slow calciumdependent spikes and plateau potentials that can reach potentials near $0 \mathrm{mV}$ (Llinás and Sugimori, 1980; Pouille et al., 2000). Unlike sodium spikes, calcium spikes are, if anything, larger in more distal dendrites (Pouille et al., 2000). It seems likely that the Kv3 channels that we found in distal as well as proximal dendrites help terminate such calcium spikes. In addition, the threshold for calcium spikes is fairly high, so that the rapidly activating potassium currents may influence the threshold. Consistent with a role of Kv3 channels in regulating calcium spikes, low concentrations of 4-AP have been found to decrease threshold and increase amplitude for calcium spikes recorded in the dendrites of guinea pig Purkinje neurons (Etzion and Grossman, 1998, 2001). The partial inactivation of the dendritic potassium currents would be expected to influence the timing of calcium spikes and plateau potentials; indeed, a role for an inactivating potassium conductance in controlling the timing and amplitude of dendritic calcium spikes has been suggested previously in turtle Purkinje cells (Midtgaard et al., 1993). Inactivation properties may also be important for climbing fiber responses that occur in rapid succession. Kv3.4 channels can dramatically change their inactivation properties after phosphorylation (Covarrubias et al., 1994), raising the possibility that modulatory transmitters could affect the integrative properties of the dendrites by this mechanism.

In many cases, Kv3 family channels have activation curves with midpoints near $10 \mathrm{mV}$ (Rudy and McBain, 2001), so that $5-10 \%$ of activation requires depolarization to approximately $-20 \mathrm{mV}$ or beyond. In contrast, the current in Purkinje neuron 
dendrites has a midpoint near $-10 \mathrm{mV}$ and significant current begins to activate at $-40 \mathrm{mV}$. In general, $\mathrm{Kv} 3$ family channels are found in soma, axons, and presynaptic terminals of fast-spiking cells, and their requirement for strong depolarization means that they are only activated during full-blown action potentials (Rudy and McBain, 2001). However, there are no full-blown sodium spikes in the dendrites of Purkinje neurons. The voltage dependence of the channels in Purkinje cell dendrites ensures that the channels can be activated even by truncated sodium spikes as well as by calcium spikes and climbing fiber responses. Yet the requirement for depolarization beyond $-40 \mathrm{mV}$ means that they will not be effectively activated by moderate-sized EPSPs from parallel fiber synapses or interfere with temporal or spatial summation of such EPSPs at subthreshold voltages.

\section{References}

Bekkers JM (2000) Distribution and activation of voltage-gated potassium channels in cell-attached and outside-out patches from large layer 5 cortical pyramidal neurons of the rat. J Physiol (Lond) 525:611-620.

Callaway JC, Ross WN (1997) Spatial distribution of synaptically activated sodium concentration changes in cerebellar Purkinje neurons. J Neurophysiol 77:145-152.

Cavelier P, Pouille F, Desplantez T, Beekenkamp H, Bossu JL (2002) Control of the propagation of dendritic low-threshold $\mathrm{Ca}^{2+}$ spikes in Purkinje cells from rat cerebellar slice cultures. J Physiol (Lond) 540:57-72.

Cingolani LA, Gymnopoulos M, Boccaccio A, Stocker M, Pedarzani P (2002) Developmental regulation of small-conductance $\mathrm{Ca}^{2+}$-activated $\mathrm{K}+$ channel expression and function in rat Purkinje neurons. J Neurosci 22:4456-4467.

Christie BR, Eliot LS, Ito K, Miyakawa H, Johnston D (1995) Different Ca ${ }^{2+}$ channels in soma and dendrites of hippocampal pyramidal neurons mediate spike-induced $\mathrm{Ca}^{2+}$ influx. J Neurophysiol 73:2553-2557.

Colbert CM, Magee JC, Hoffman DA, Johnston D (1997) Slow recovery from inactivation of $\mathrm{Na}+$ channels underlies the activity-dependent attenuation of dendritic action potentials in hippocampal CA1 pyramidal neurons. J Neurosci 17:6512-6521.

Covarrubias M, Wei A, Salkoff L, Vyas TB (1994) Elimination of rapid potassium channel inactivation by phosphorylation of the inactivation gate. Neuron 13:1403-1412.

Diochot S, Schweitz H, Béress L, Lazdunski M (1998) Sea anemone peptides with a specific blocking activity against the fast inactivating potassium channel Kv3.4. J Biol Chem 273:6744-6749.

Eccles JC, Llinas R, Sasaki K (1966) The excitatory synaptic action of climbing fibres on the purkinje cells of the cerebellum. J Physiol (Lond) 182:268-296.

Edgerton JR, Reinhart PH (2003) Distinct contributions of small and large conductance $\mathrm{Ca}^{2+}$-activated $\mathrm{K}+$ channels to rat Purkinje neuron function. J Physiol (Lond) 548:53-69.

Etzion Y, Grossman Y (1998) Potassium currents modulation of calcium spike firing in dendrites of cerebellar Purkinje cells. Exp Brain Res 122:283-294.

Etzion Y, Grossman Y (2001) Highly 4-aminopyridine sensitive delayed rectifier current modulates the excitability of guinea pig cerebellar Purkinje cells. Exp Brain Res 139:419-425.

Gähwiler BH, Llano I (1989) Sodium and potassium conductances in somatic membranes of rat Purkinje cells from organotypic cerebellar cultures. J Physiol (Lond) 417:105-122.

Golding NL, Jung HY, Mickus T, Spruston N (1999) Dendritic calcium spike initiation and repolarization are controlled by distinct potassium channel subtypes in CA1 pyramidal neurons. J Neurosci 19:8789-8798.

Golding NL, Kath WL, Spruston N (2001) Dichotomy of action-potential backpropagation in CA1 pyramidal neuron dendrites. J Neurophysiol 86:2998-3010.

Goldman-Wohl D, Chan E, Baird D, Heintz N (1994) Kv3.3b: a novel shaw type potassium channel expressed in terminally differentiated cerebellar Purkinje cells and deep cerebellar nuclei. J Neurosci 14:511-522.

Grissmer S, Nguyen AN, Aiyar J, Hanson DC, Mather RJ, Gutman GA, Karmilowicz MJ, Auperin DD, Chandy KG (1994) Pharmacological characterization of five cloned voltage-gated $\mathrm{K}+$ channels, types Kv1.1,
$1.2,1.3,1.5$, and 3.1, stably expressed in mammalian cell lines. Mol Pharmacol 45:1227-1234.

Gruol DL, Dionne VE, Yool AJ (1989) Multiple voltage-sensitive K+ channels regulate dendritic excitability in cerebellar Purkinje neurons. Neurosci Lett 97:97-102.

Gruol DL, Jacquin T, Yool AJ (1991) Single-channel K+ currents recorded from the somatic and dendritic regions of cerebellar Purkinje neurons in culture. J Neurosci 11:1002-1015.

Häusser M, Clark BA (1997) Tonic synaptic inhibition modulates neuronal output pattern and spatiotemporal synaptic integration. Neuron 19:665-678.

Häusser M, Spruston N, Stuart GJ (2000) Diversity and dynamics of dendritic signaling. Science 290:739-744.

Hoffman DA, Magee JC, Colbert CM, Johnston D (1997) K+ channel regulation of signal propagation in dendrites of hippocampal pyramidal neurons. Nature 387:869-875.

Hoffman DA, Johnston D (1998) Downregulation of transient K+ channels in dendrites of hippocampal CA1 pyramidal neurons by activation of PKA and PKC. J Neurosci 18:3521-3528.

Jacquin TD, Gruol DL (1999) $\mathrm{Ca}^{2+}$ regulation of a large conductance $\mathrm{K}+$ channel in cultured rat cerebellar Purkinje neurons. Eur J Neurosci 11:735-739.

Johnston D, Magee JC, Colbert CM, Cristie BR (1996) Active properties of neuronal dendrites. Annu Rev Neurosci 19:165-186.

Johnston D, Hoffman DA, Magee JC, Poolos NP, Watanabe S, Colbert CM, Migliore M (2000) Dendritic potassium channels in hippocampal pyramidal neurons. J Physiol (Lond) 525:75-81.

Jung HY, Mickus T, Spruston N (1997) Prolonged sodium channel inactivation contributes to dendritic action potential attenuation in hippocampal pyramidal neurons. J Neurosci 17:6639-6646.

Korngreen A, Sakmann B (2000) Voltage gated K+ channels in layer 5 neocortical pyramidal neurons from young rats: subtypes and gradients. J Physiol (Lond) 525:621-639.

Laube G, Röper J, Pitt JC, Sewing S, Kistner U, Garner C, Pongs O, Veh RW (1996) Ultrasructural localization of Shaker-related potassium channels subunits and synapse-associated protein 90 to septate-like junctions in rat cerebellar Pinceaux. Mol Brain Res 42:51-61.

Lien CC, Martina M, Schultz JH, Ehmke H, Jonas P (2002) Gating, modulation and subunit composition of voltage-gated $\mathrm{K}^{+}$channels in dendritic inhibitory interneurones of rat hippocampus. J Physiol (Lond) 538:405-419.

Llinás R, Sugimori M (1980) Electrophysiological properties of in vitro Purkinje cell dendrites in mammalian cerebellar slices. J Physiol (Lond) 305:197-213.

Maletic-Savatic M, Lenn NJ, Trimmer JS (1995) Differential spatiotemporal expression of $\mathrm{K}+$ channel polypeptides in rat hippocampal neurons developing in situ and in vitro. J Neurosci 15:3840-3851.

Martina M, Schultz JH, Ehmke H, Monyer H, Jonas P (1998) Functional and molecular differences between voltage-gated $\mathrm{K}+$ channels of fast spiking interneurons and pyramidal neurons of rat hippocampus. J Neurosci 18:8111-8125.

Martina M, Vida I, Jonas P (2000) Distal initiation and active propagation of action potentials in interneuron dendrites. Science 287:295-300.

Midtgaard J, Lasser-Ross N, Ross WN (1993) Spatial distribution of $\mathrm{Ca}^{2+}$ influx in turtle Purkinje cell dendrites in vitro: role of a transient outward current. J Neurophysiol 70:2455-2469.

Mouginot D, Bossu J, Gahwiler B (1997) Low-threshold $\mathrm{Ca}^{2+}$ currents in dendritic recordings from Purkinje cells in rat cerebellar slice cultures. J Neurosci 17:160-170.

Oakley JC, Schwindt PC, Crill WE (2001) Dendritic calcium spikes in layer 5 pyramidal neurons amplify and limit transmission of ligand-gated dendritic current to soma. J Neurophysiol 86:514-527.

Pak MD, Baker K, Covarrubias M, Butler A, Ratcliffe A, Salkoff L (1991) mShal, a subfamily of A-type $\mathrm{K}+$ channel cloned from mammalian brain. Proc Natl Acad Sci USA 88:4386-4390.

Pouille F, Cavelier P, Desplantez T, Beekenkamp H, Craig PJ, Beattie RE, Volsen SG, Bossu JL (2000) Dendro-somatic distribution of calciummediated electrogenesis in purkinje cells from rat cerebellar slice cultures. J Physiol (Lond) 527:265-282.

Raman IM, Bean BP (1999) Ionic currents underlying spontaneous action potentials in isolated cerebellar purkinje neurons. J Neurosci 19:1663-1674. 
Rashid AJ, Dunn RJ, Turner RW (2001) A prominent soma-dendritic distribution of $\mathrm{Kv} 3.3 \mathrm{~K}+$ channels in electrosensory and cerebellar neurons. J Comp Neurol 441:234-247.

Rettig J, Wunder F, Stocker M, Lichtinghagen R, Mastiaux F, Beckh S, Kues W, Pedarzani P, Schroter KH, Ruppersberg JP (1992) Characterization of a Shaw-related potassium channel family in rat brain. EMBO J 11:2473-2486.

Roth A, Häusser M (2001) Compartmental models of rat cerebellar Purkinje cells based on simultaneous somatic and dendritic patch-clamp recordings. J Physiol (Lond) 535:445-472.

Rudy B, McBain CJ (2001) Kv3 channels: voltage-gated K+ channels designed for high-frequency repetitive firing. Trends Neurosci 24:517-526.

Sacco T, Tempia F (2002) A-type potassium currents active at subthreshold potentials in mouse cerebellar Purkinje cells. J Physiol (Lond) 543:505-520.

Southan AP, Robertson B (2000) Electrophysiological characterization of voltage-gated $\mathrm{K}+$ currents in cerebellar basket and Purkinje cells: Kv1 and $\mathrm{Kv} 3$ channel subfamilies are present in basket cell nerve terminals. J Neurosci 20:114-122.

Spruston N, Stuart GJ, Häusser M (1999) Dendritic integration. In: Dendrites (Stuart G, Spruston N, Häusser M, eds). Oxford: Oxford UP.

Stuart G, Dodt HU, Sakmann B (1993) Patch-clamp recordings from the soma and dendrites of neurons in brain slices using infrared video microscopy. Pflügers Arch 423:511-518.

Stuart G, Häusser M (1994) Initiation and spread of sodium action potentials in cerebellar Purkinje cells. Neuron 13:703-712.

Stuart GJ, Häusser M (2001) Dendritic coincidence detection of EPSPs and action potentials. Nat Neurosci 4:63-71.

Usowicz MM, Sugimori M, Cherksey B, Llinás R (1992) P-type calcium channels in the somata and dendrites of adult cerebellar Purkinje cells. Neuron 9:1185-1199.

Veh RW, Lichtinghagen R, Sewing S, Wunder F, Grumbach IM, Pongs O (1995) Immunohistochemical localization of five members of the Kv1 channel subunits: contrasting subcellular locations and neuron-specific co-localizations in rat brain. Eur J Neurosci 7:2189-21205.

Vetter P, Roth A, Häusser M (2001) Propagation of action potentials in dendrites depends on dendritic morphology. J Neurophysiol 85:926-937.
Vullhorst D, Jockusch H, Bartsch JW (2001) The genomic basis of K(V)3.4 potassium channel mRNA diversity in mice. Gene 264:29-35.

Watanabe S, Hoffman DA, Migliore M, Johnston D (2002) Dendritic $\mathrm{K}+$ channels contribute to spike-timing dependent long-term potentiation in hippocampal pyramidal neurons. Proc Natl Acad Sci USA 99:8366-8371.

Weiser M, Vega-Saenz de Miera E, Kentros C, Moreno H, Franzen L, Hillmann D, Baker H, Rudy B (1994) Differential expression of Shawrelated K+ channels in the rat CNS. J Neurosci 14:949-972.

Weiser M, Bueno E, Sekirnjak C, Martone ME, Baker H, Hillman D, Chen S, Thornhill W, Ellisman M, Rudy B (1995) The potassium channel subunit KV3.1b is localized to somatic and axonal membranes of specific populations of CNS neurons. J Neurosci 15:4298-4314.

Westenbroek RE, Sakurai T, Elliott EM, Hell JW, Starr TV, Snutch TP, Catterall WA (1995) Immunochemical identification and subcellular distribution of the alpha 1A subunits of brain calcium channels. J Neurosci 15:6403-6418.

Williams SR, Stuart GJ (2000) Backpropagation of physiological spike trains in neocortical pyramidal neurons: implications for temporal coding in dendrites. J Neurosci 20:8238-8246.

Womack MD, Khodakhah K (2002a) Characterization of large conductance $\mathrm{Ca}^{2+}$-activated $\mathrm{K}+$ channels in cerebellar Purkinje neurons. Eur J Neurosci 16:1214-1222.

Womack MD, Khodakhah K (2002b) Active contribution of dendrites to the tonic and trimodal patterns of activity in cerebellar Purkinje neurons. J Neurosci 22:10603-10612.

Womack MD, Khodakhah K (2003) Somatic and dendritic smallconductance calcium-activated potassium channels regulate the output of cerebellar Purkinje neurons. J Neurosci 23:2600-2607.

Yokoyama CT, Westenbroek RE, Hell JW, Soong TW, Snutch TP, Catterall WA (1995) Biochemical properties and subcellular distribution of the neuronal class E calcium channel alpha 1 subunit. J Neurosci 15:6419-6432.

Yool AJ, Dionne VE, Gruol DL (1988) Developmental changes in K+selective channel activity during differentiation of the Purkinje neuron in culture. J Neurosci 8:1971-1980. 